\title{
PENGARUH LAMA PEREBUSAN TERHADAP KARAKTERISTIK LOLOH DON PIDUH \\ (Centella asiatica L.)
}

The Effect of Boiling Time on The Characteristics of Loloh Don Piduh (Centella asiatica L.)

\author{
I Gusti Ngurah Arry Putra'), Ni Luh Ari Yusasrini ${ }^{2)}$, I Wayan Rai Widarta ${ }^{2)}$ \\ ${ }^{1)}$ Mahasiswa Program Studi Imu dan Teknologi Pangan, Fakultas Teknologi Pertanian, Unud \\ ${ }^{2}$ Dosen Program Studi Imu dan Teknologi Pangan, Fakultas Teknologi Pertanian, Unud \\ Kampus Bukit Jimbaran, Badung-Bali
}

\begin{abstract}
$A B S T R A C T$
This study aims to determine the effect of boiling time to the characteristics of loloh don piduh (Centella asiatica L.) and the appropriate boiling time to produce loloh don piduh with the best characteristics. The experimental design used was a complete randomized design with 6 treatment levels: T1 (25 minutes), T2 (40 minutes), T3 (55 minutes), T4 (70 minutes), T5 (85 minutes) and T6 (100 minutes). The treatment was repeated 3 times to obtain 18 units of experiment. The data obtained were analyzed by variance and if the treatment had an effect on the observed variable then continued with Duncan test. The boiling time had a very significant effect on antioxidant activity, vitamin $C$ levels, and the level of panelist preferences for taste and overall acceptance of loloh don piduh. Boiling time had a significant effect on total soluble solids (TSS) of loloh don piduh. Boiling time had no significantly affect on panelist preferences for the color and flavor of loloh don piduh. 25 minutes boiling time had produced loloh don piduh with the best characteristics of: antioxidant activity 90,82\%, vitamin C levels $0,11 \%$, total soluble solids (TSS) of $2^{\circ}$ brix, panelist preferences for color, flavor, taste, and overall acceptance was preferred.
\end{abstract}

Keywords: Centella asiatica, boiling time, loloh don piduh

\section{PENDAHULUAN}

Loloh adalah minuman tradisional yang banyak dikonsumsi oleh masyarakat Bali, yang memiliki efek fisiologis bagi tubuh (Kusumawati et al., 2014). Loloh sudah tidak asing lagi di mata masyarakat Bali. Beberapa loloh yang sering dijumpai di pasaran berdasarkan bahan bakunya antara lain loloh kunyit, loloh cem-cem, loloh daun sirih dan loloh sambiloto. Loloh memiliki khasiat masing-masing tergantung dari bahan baku pembuatan loloh. Sejak tahun 2014 Walikota Denpasar telah rutin memperkenalkan minuman obat tradisional berupa loloh siap minum kepada masyarakat Bali. Adanya keinginan tersebut maka dibuat dan diperkenalkan produk loloh yang salah satunya yaitu loloh don piduh. Bahan baku utama untuk pembuatan loloh don piduh ini adalah daun pegagan (Centella asiatica L.) yang bisa ditanam dan dibudidayakan sendiri. Selain itu dalam pembuatan loloh don piduh dapat juga ditambahkan bahan tambahan lain seperti gula dan jeruk nipis (Sari et al., 2017). Loloh don piduh dapat dibuat dengan cara mencampur air dengan daun pegagan kemudian direbus dan disaring air rebusannya serta ditambahkan bahan tambahan seperti gula, jeruk nipis, dan madu untuk memperkuat cita rasa (Tusta, 2016).

Pegagan secara tradisional banyak

\footnotetext{
*Korespondensi Penulis:

E-mail: nguraharryputra@gmail.com ${ }^{1)}$
} 
digunakan untuk penyakit kulit (Padua, 1999). Di samping itu menurut (Januawati dan Yusron, 2004), pegagan juga digunakan untuk mengobati sakit perut, batuk, batuk berdarah dan disentri, penyembuh luka, radang, pegal linu, asma, wasir, tuberkulosis, lepra, demam dan penambah selera makan. Daun pegagan juga mengandung beberapa senyawa aktif seperti triterpenoid saponin, triterpenoid genin, minyak essensial, dan flavonoid (Winarto dan Surbakti, 2003). Disamping senyawa tersebut, juga banyak dijumpai senyawa lainnya termasuk asam askorbat (Sharma dan Jaimala 2003). Di dalam pegagan juga ditemukan senyawa flavonoid lainnya seperti castilliferol, castillicetin, dan isochlorogenic acid yang diketahui adalah sebagai antioksidan yang kuat (Hussin, 2007), dan Subban et al., (2008). Keistimewaan daun pegagan yang simplisianya dikenal dengan sebutan Centella Herba memiliki kandungan senyawa triterpenoida yaitu Asiatic acid, Madaciatic acid, Asiaticoside, Madecassoside yang bermanfaat meningkatkan vitalitas dan daya ingat serta mengatasi pikun, serta garam mineral seperti kalium, natrium, magnesium, kalsium dan besi yang bermanfaat untuk kesehatan tulang, penurunan tekanan darah tinggi, menurunkan resiko terkena stroke, dan menjaga fungsi otak (Dahono, 2010). Penelitian Maulidzy dan Dwijayanti (2016) menyatakan bahwa aktivitas antioksidan ekstrak daun pegagan yang dianalisis menggunakan nilai $\mathrm{EC}_{50}$ dengan pelarut air adalah sebesar $2,70 \%$ dan $2,31 \%$ dengan pelarut etanol.

Pada umumnya pembuatan loloh sangat sederhana, sehingga dapat dibuat dengan mudah oleh masyarakat. Produsen loloh pada umumnya seringkali masih jarang memperhatikan cara pengolahan loloh. Cara pengolahan yang dimaksud adalah pada proses perebusan loloh yang menggunakan waktu perebusan yang cukup lama yang akan mengakibatkan menurunnya kandungan gizi terutama senyawa yang larut dalam air seperti vitamin $\mathrm{C}$ dan antioksidan. Semakin tinggi suhu dan waktu pemanasan mengakibatkan senyawa metabolit sekunder yang bertindak sebagai antioksidan (senyawa flavonoid) dan kandungan vitamin $\mathrm{C}$ dalam suatu bahan akan rusak (Aisyah, 2014). Rahmawati et al., (2013) menyatakan bahwa senyawa flavonoid akan rusak sehingga kurang mampu mereduksi radikal bebas dengan baik. Selain itu, vitamin $\mathrm{C}$ yang terkandung dalam suatu bahan mudah teroksidasi dan proses oksidasi tersebut dipercepat oleh adanya pemanasan. Andarwulan et al., (2011) juga menambahkan bahwa perlakuan panas yang diberikan pada waktu memasak sayuran mengakibatkan kerusakan vitamin $\mathrm{C}$ dan aktivitas antioksidan yang besarnya lebih dari 50\% selama 1 jam. Ramdhan dan Aminah (2014) juga menyatakan vitamin $\mathrm{C}$ mulai mengalami kerusakan pada suhu $95-100^{\circ} \mathrm{C}$ dengan waktu pemanasan 5 menit. Oleh karena itu perlu dilakukan penelitian untuk mengetahui lama perebusan yang tepat untuk menghasilkan loloh don piduh dengan karakteristik terbaik.

\section{METODE PENELITIAN}

\section{Tempat dan Waktu}

Penelitian ini dilakukan di Laboratorium Pengolahan Pangan dan Analisis Pangan, Program Studi Ilmu dan Teknologi Pangan, Fakultas Teknologi Pertanian Universitas Udayana, Jalan Jendral Sudirman, Denpasar, Gedung Agrokomplek Universitas Udayana dan Laboratorium Rekayasa Proses dan Pengendalian Mutu, Gedung G.A. Fakultas Teknologi Pertanian, Universitas Udayana Bukit Jimbaran. Penelitian ini dilakukan selama 3 bulan, dimulai dari bulan Oktober 2017 sampai dengan Januari 2018.

\section{Bahan dan Alat}

Bahan yang digunakan dalam penelitian ini, antara lain : daun pegagan dengan kriteria daun tua dengan ciri-ciri warna daun hijau tua yang diperoleh di Br. Pokas Blahbatuh, 
Gianyar, kemasan botol plastik $330 \mathrm{ml}$, jeruk nipis, madu, gula, metanol, KI, I $2,2,2-$ diphenyl-1-picrylhidrazyl (DPPH) (Aldrich), larutan amilum 1\%, akuades, kertas saring, aluminium foil, dan kertas label.

Alat yang digunakan dalam penelitian ini, antara lain : spektrofotometer (Genesys 10S UV-UI5), $\quad 0-80 \%$ brix refractometer, timbangan analitik (Shimadzu), tabung reaksi, gelas ukur, labu erlenmeyer, pipet tetes, pipet mikro, pipet volume, buret, bulb, rak tabung, vortex, labu takar, spatula/sutil, kompor (Rinnai), wajan, gunting, dan pisau.

\section{Rancangan Percobaan}

Rancangan percobaan yang digunakan adalah rancangan acak lengkap dengan 6 taraf perlakuan : T1 (25 menit), T2 (40 menit), T3 (55 menit), T4 (70 menit), T5 (85 menit) dan T6 (100 menit). Perlakuan diulang sebanyak 3 kali sehingga didapat 18 unit percobaan. Data yang diperoleh dianalisis dengan sidik ragam dan apabila perlakuan berpengaruh terhadap variabel yang diamati maka dilanjutkan dengan uji Duncan (Steel dan Torrie, 1993).

\section{Pelaksanaan Penelitian \\ Pemetikan dan Sortasi Daun Pegagan}

Daun pegagan diperoleh di $\mathrm{Br}$. Pokas Blahbatuh, Gianyar dengan kriteria daun tua berwarna hijau tua dipetik dengan menyisakan tangkai daun sepanjang $\pm 1 \mathrm{~cm}$ dan dicuci dengan air mengalir hingga bersih.

\section{Pembuatan Loloh Don Piduh}

Daun pegagan yang telah disortasi ditimbang masing-masing sebanyak 50 gram. Kemudian dipanaskan air sebanyak $500 \mathrm{ml}$ hingga mendidih dengan suhu $95-100^{\circ} \mathrm{C}$. Setelah mendidih, daun pegagan direbus sebanyak 50 gram dengan lama perebusan sesuai dengan perlakuan (25 menit, 40 menit, 55 menit, 70 menit, 85 menit dan 100 menit). Setelah itu, air rebusan daun pegagan kemudian didinginkan selama 10 menit agar tidak terlalu panas, lalu disaring. Selanjutnya ditambahkan bahan tambahan perasan jeruk nipis, madu dan gula sebanyak $1 \%$ dari volume akhir masing-masing proses perebusan. Setelah dilakukan pengadukan kemudian langsung dikemas dengan kemasan botol plastik.

\section{HASIL DAN PEMBAHASAN}

Hasil analisis kadar vitamin C, aktivitas antioksidan dan total padatan terlarut (TSS) dari loloh don piduh terdapat pada Tabel 1.

Tabel 1. Nilai rata-rata kadar vitamin C, aktivitas antioksidan dan total padatan terlarut (TSS) loloh don piduh.

\begin{tabular}{cccc}
\hline $\begin{array}{c}\text { Perlakuan } \\
\text { Lama Perebusan }\end{array}$ & Kadar Vitamin C (\%) & Aktivitas Antioksidan (\%) & $\begin{array}{c}\text { Total Padatan Terlarut (TSS) } \\
\left({ }^{\circ} \text { brix }\right)\end{array}$ \\
\hline 25 menit (T1) & $0,11 \pm 0,005 \mathrm{a}$ & $90,82 \pm 0,46 \mathrm{a}$ & $2,00 \pm 0 \mathrm{c}$ \\
40 menit (T2) & $0,10 \pm 0,005 \mathrm{~b}$ & $90,13 \pm 0,17 \mathrm{~b}$ & $2,17 \pm 0,28 \mathrm{bc}$ \\
55 menit (T3) & $0,09 \pm 0 \mathrm{c}$ & $89,54 \pm 0,29 \mathrm{bc}$ & $2,33 \pm 0,28 \mathrm{abc}$ \\
70 menit (T4) & $0,08 \pm 0,0005 \mathrm{~d}$ & $89,01 \pm 0,49 \mathrm{c}$ & $2,50 \pm 0 \mathrm{ab}$ \\
85 menit (T5) & $0,07 \pm 0,0005 \mathrm{e}$ & $88,36 \pm 0,40 \mathrm{~d}$ & $2,50 \pm 0 \mathrm{ab}$ \\
100 menit (T6) & $0,07 \pm 0,0005 \mathrm{e}$ & $87,10 \pm 0,09 \mathrm{e}$ & $2,67 \pm 0,28 \mathrm{a}$ \\
\hline
\end{tabular}

Keterangan : Nilai rata - rata yang diikuti oleh huruf yang berbeda pada kolom yang sama menunjukkan berbeda nyata pada Uji Duncan $(\mathrm{P}<0,05)$. 


\section{Kadar Vitamin C Loloh Don Piduh}

Hasil sidik ragam menunjukkan bahwa lama perebusan berpengaruh sangat nyata $(\mathrm{P}<0,01)$ terhadap vitamin $\mathrm{C}$ loloh don piduh. Tabel 1 menunjukkan kadar vitamin C loloh don piduh berkisar 0,07 \% sampai dengan $0,11 \%$. Vitamin $\mathrm{C}$ tertinggi diperoleh dari loloh don piduh pada perlakuan T1 (25 menit) yaitu $0,11 \%$, sedangkan vitamin $\mathrm{C}$ terendah diperoleh dari loloh don piduh pada perlakuan T5 (85 menit) yaitu $0,07 \%$ yang tidak berbeda nyata dengan perlakuan T6 (100 menit). Semakin lama proses pemanasan maka kadar vitamin $\mathrm{C}$ loloh don piduh semakin menurun karena terjadinya proses oksidasi, Winarno (2002) melaporkan bahwa vitamin $\mathrm{C}$ mudah teroksidasi selama proses pengolahan yang dipercepat oleh panas, alkali, enzim dan oksidator. Ramdhan dan Aminah (2014) menyatakan vitamin $C$ mulai mengalami kerusakan pada suhu $95-100^{\circ} \mathrm{C}$ dengan waktu pemanasan 5 menit.

\section{Aktivitas Antioksidan Loloh Don Piduh}

Hasil sidik ragam menunjukkan bahwa lama perebusan berpengaruh sangat nyata $(\mathrm{P}<0,01)$ terhadap aktivitas antioksidan loloh don piduh. Tabel 1 menunjukkan aktivitas antioksidan loloh don piduh berkisar 87,10\% sampai dengan 90,82\%. Aktivitas antioksidan loloh don piduh tertinggi diperoleh dari pada perlakuan T1 (25 menit) yaitu 90,82 \%, sedangkan aktivitas antioksidan loloh don piduh terendah diperoleh dari pada perlakuan T6 (100 menit) yaitu 87,10\%. Semakin lama perebusan, aktivitas antioksidan loloh don piduh semakin menurun dikarenakan senyawa bioaktif yang terkandung dalam daun pegagan mengalami kerusakan oleh pemanasan dengan waktu yang lama. Disamping itu nilai aktivitas antioksidan loloh don piduh semakin menurun disebabkan juga karena menurunnya kadar vitamin $\mathrm{C}$ loloh don piduh selama proses perebusan. Pokorny et al., (2001) melaporkan bahwa pemanasan menyebabkan percepatan reaksi inisiasi dan penurunan aktivitas antioksidan dikarenakan senyawa metabolit sekunder yang bertindak sebagai antioksidan (senyawa flavonoid) rusak sehingga kurang mampu mereduksi radikal bebas dengan baik. Kumalaningsih (2006) menyatakan bahwa vitamin $\mathrm{C}$ merupakan donor elektron dan agen pereduksi. Disebut antioksidan, karena dengan mendonorkan elektronnya, vitamin ini mencegah senyawasenyawa lain agar tidak teroksidasi. Aktivitas antioksidan yang tinggi pada loloh don piduh juga disebabkan karena adanya penambahan bahan tambahan madu dan jeruk nipis dalam proses pembuatannya. Winarno (1982) melaporkan bahwa madu memiliki efek antioksidan karena mengandung vitamin $\mathrm{C}$, flavonoid, mangan, dan beta karoten, selain itu jeruk nipis juga mengandung vitamin $\mathrm{C}$ yang juga berperan sebagai antioksidan.

\section{Total Padatan Terlarut (TSS) Loloh Don Piduh}

Hasil sidik ragam menunjukkan bahwa lama perebusan berpengaruh nyata $(\mathrm{P}<0,05)$ terhadap total padatan terlarut loloh don piduh. Tabel 1 menunjukkan total padatan terlarut loloh don piduh berkisar 2,00 sampai dengan 2,67. Total padatan terlarut loloh don piduh terendah diperoleh dari perlakuan T1 (25 menit), sedangkan total padatan terlarut loloh don piduh dengan nilai tertinggi diperoleh dari perlakuan T6 (100 menit). Semakin lama perebusan maka total padatan terlarut loloh don piduh semakin meningkat yang ditandai dengan kenampakan loloh don piduh yang semakin pekat dan warna yang semakin gelap. Hal ini didukung oleh Suyitno (1989) yang menyatakan bahwa ekstraksi dengan menggunakan pelarut air, komponen lain yang terdapat dalam bahan akan ikut terekstrak. Giovannucci mengungkapkan bahwa semakin tinggi suhu dan semakin lama proses perebusan, maka semakin tinggi pula total padatan tarlarut 
yang dihasilkan. Hal tersebut terjadi karena pengaruh suhu perebusan yang tinggi dan waktu perebusan yang semakin meningkat, menyebabkan hidrolitik yang berlebihan sehingga ekstrak yang dihasilkan lebih pekat, sehingga nilai total padatan terlarut yang terukur semakin tinggi.

\section{Karakterstik Sensoris Loloh Don Piduh}

Karakteristik sensoris loloh don piduh dilakukan dengan uji hedonik terhadap warna, aroma, rasa dan penerimaan keseluruhan. Nilai rata-rata uji hedonik terhadap warna, aroma, rasa dan penerimaan keseluruhan loloh don piduh dapat dilihat pada Tabel 2.

Tabel 2. Nilai rata - rata uji hedonik warna, aroma, rasa dan penerimaan keseluruhan loloh don piduh.

\begin{tabular}{ccccc}
\hline \multirow{2}{*}{ Perlakuan Lama Perebusan } & \multicolumn{4}{c}{ Nilai Rata-rata Uji Hedonik } \\
\cline { 2 - 5 } & Warna & Aroma & Rasa & Penerimaan Keseluruhan \\
\hline 25 menit (T1) & $6,40 \pm 0,63 \mathrm{a}$ & $6,13 \pm 0,64 \mathrm{a}$ & $6,60 \mathrm{a} \pm 0,63 \mathrm{a}$ & $6,53 \pm 0,64 \mathrm{a}$ \\
40 menit (T2) & $5,53 \pm 0,83 \mathrm{a}$ & $5,80 \pm 0,86 \mathrm{a}$ & $5,67 \mathrm{~b} \pm 0,72 \mathrm{~b}$ & $5,60 \pm 0,63 \mathrm{~b}$ \\
55 menit (T3) & $5,67 \pm 0,61 \mathrm{a}$ & $5,53 \pm 0,83 \mathrm{a}$ & $5,60 \mathrm{~b} \pm 0,74 \mathrm{~b}$ & $5,53 \pm 0,52 \mathrm{~b}$ \\
70 menit (T4) & $6,00 \pm 0,65 \mathrm{a}$ & $5,67 \pm 0,81 \mathrm{a}$ & $5,60 \mathrm{~b} \pm 0,91 \mathrm{~b}$ & $5,73 \pm 0,88 \mathrm{~b}$ \\
85 menit (T5) & $5,93 \pm 0,59 \mathrm{a}$ & $5,93 \pm 0,70 \mathrm{a}$ & $5,47 \mathrm{~b} \pm 1,06 \mathrm{~b}$ & $5,60 \pm 0,91 \mathrm{~b}$ \\
100 menit (T6) & $5,80 \pm 0,56 \mathrm{a}$ & $6,07 \pm 0,59 \mathrm{a}$ & $5,27 \mathrm{~b} \pm 0,88 \mathrm{~b}$ & $5,47 \pm 0,64 \mathrm{~b}$ \\
\hline
\end{tabular}

Keterangan : Nilai rata - rata yang diikuti oleh huruf yang berbeda pada kolom yang sama menunjukkan berbeda nyata pada Uji Duncan $(\mathrm{P}<0,05)$.

\section{Warna}

Hasil sidik ragam menunjukkan bahwa lama perebusan tidak berpengaruh nyata $(\mathrm{P}>0,05)$ terhadap kesukaan warna loloh don piduh. Tabel 2 menunjukkan bahwa nilai ratarata tingkat kesukaan panelis terhadap warna loloh don piduh berkisar dari 5,53 (suka) hingga 6,40 (suka). Warna merupakan komponen penting untuk menentukan derajat penerimaan suatu bahan pangan Winarno (2004).

\section{Aroma}

Hasil sidik ragam menunjukkan bahwa lama perebusan tidak berpengaruh nyata $(\mathrm{P}>0,05)$ terhadap kesukaan aroma loloh don piduh. Tabel 2 menunjukkan bahwa nilai ratarata tingkat kesukaan panelis terhadap aroma loloh don piduh berkisar dari 5,53 (suka) hingga 6,13 (suka). Meilgaard et al., (2000) mengungkapkan aroma makanan timbul karena terbentuknya senyawa volatil. Fellow (1988) melaporkan bahwa senyawa volatil dapat hilang selama proses pengolahan terutama dengan panas.

\section{Rasa}

Hasil sidik ragam menunjukkan bahwa lama perebusan berpengaruh sangat nyata $(\mathrm{P}<0,01)$ terhadap kesukaan rasa loloh don piduh. Tabel 2 menunjukkan bahwa nilai ratarata tingkat kesukaan panelis terhadap rasa tertinggi diperoleh dari loloh don piduh dari perlakuan T1 (25 menit) yaitu 6,60 (suka), sedangkan nilai rata-rata terendah diperoleh dari loloh don piduh pada perlakuan T6 (100 menit) yaitu 5,27 (agak suka) yang tidak berbeda nyata dengan perlakuan T2-T5. Semakin lama perebusan maka tingkat kesukaan panelis terhadap rasa loloh don piduh semakin menurun. Meena et al., (2012) melaporkan bahwa tanin merupakan salah satu zat yang terkandung dalam pegagan. Menurut Makfoeld (1992) salah satu sifat tanin adalah larut dalam air dan jika diberikan perlakuan pemanasan dengan waktu yang lama akan mengakibatkan senyawa tanin mengalami penguraian (dekomposisi) dan perubahan sifat fisikokimia dapat membentuk larutan koloidal yang menghasilkan rasa sepat. 


\section{Penerimaan Keseluruhan}

Hasil sidik ragam menunjukkan bahwa lama perebusan berpengaruh sangat nyata $(\mathrm{P}<0,01)$ terhadap kesukaan penerimaan keseluruhan loloh don piduh. Tabel 2 menunjukkan bahwa nilai rata-rata tingkat kesukaan panelis terhadap rasa tertinggi diperoleh dari loloh don piduh dari perlakuan T1 (25 menit) yaitu 6,53 (suka), sedangkan nilai rata-rata terendah diperoleh dari loloh don piduh pada perlakuan T6 (100 menit) yaitu 5,47 (agak suka) yang tidak berbeda nyata dengan perlakuan T2-T5. Penerimaan keseluruhan loloh don piduh dipengaruhi oleh beberapa faktor seperti warna, aroma, dan rasa.

\section{SIMPULAN DAN SARAN}

\section{Simpulan}

Berdasarkan hasil penelitian ini dapat disimpulkan bahwa lama perebusan berpengaruh sangat nyata terhadap aktivitas antioksidan, kadar vitamin $\mathrm{C}$, tingkat kesukaan panelis terhadap rasa dan penerimaan keseluruhan loloh don piduh. Lama perebusan berpengaruh nyata terhadap total padatan terlarut (TSS) loloh don piduh. Lama perebusan tidak berpengaruh nyata terhadap tingkat kesukaan panelis terhadap warna dan aroma loloh don piduh. Lama perebusan 25 menit memperoleh loloh don piduh dengan karakteristik terbaik yaitu : aktivitas antioksidan sebesar 90,82 \%, kadar vitamin sebesar $\mathrm{C} 0,11 \%$, total padatan terlarut (TSS) sebesar $2^{\circ}$ brix, tingkat kesukaan panelis terhadap warna, aroma, rasa dan penerimaan keseluruhan yang disukai.

\section{Saran}

Berdasarkan hasil penelitian ini dapat disarankan agar menggunakan lama perebusan 25 menit dalam pembuatan loloh don piduh dan perlu dilakukan penelitian lebih lanjut mengenai senyawa yang bersifat sebagai antioksidan pada loloh don piduh secara kuantitatif.

\section{DAFTAR PUSTAKA}

Aisyah, L. 2014. Pengaruh pemanasan terhadap aktivitas antioksidan pada beberapa jenis sayuran. Jurnal Teknologi dan Industri Pertanian Indonesia. 6 (2):28-32.

Andarwulan, N., F. Kusnandar dan D. Herawati. 2011. Analisis Pangan. Dian Rakyat, Jakarta.

Dahono, 2010. Tanaman Pegagan. Loka Pengkajian Teknologi Pertanian (LPTP) Kepulauan Riau, Riau.

Fellow, P.J. 1988. Food Processing Technology Principle and Practice. Ellis Horwood, New York.

Giovannucci, E. 1999. Tomatoes, tmato-based product, lycopene, and cancer. Journal of The National Cancer Institute. 91:317-331.

Hussin. 2007. Protective effect of Centella asiatica extract and powder on oxidative stress in rats. Food Chemistry. 100:535-541.

Januwati M, dan Yusron. 2004. Standar Operasional: Budidaya Pegagan, Lidah Buaya, Sambiloto dan Kumis Kucing. Erlangga, Bogor.

Khasanah, U. 2003. Formulasi Karakterisasi Fisiko-Kimia dan Organoleptik Produk Makanan Sarapan Ubi Jalar (Sweet Potato Flakes). Skripsi. Tidak dipublikasi. Fakultas Teknologi Pertanian. Institut Pertanian Bogor, Bogor.

Kumalaningsih, S. 2006. Antioksidan Alami: Penangkal Radikal Bebas, Sumber, Manfaat, Cara Penyediaan dan 
Pengolahan. Trubus Agrisarana, Surabaya.

Kusumawati, 2014. Potensi Antioksidan Loloh Tempuyung (Sonchusarvensis L.) Sebagai Minuman Fungsional. Fakultas Ilmu Kesehatan, Sains dan Teknologi Universitas Dhyana Pura. Bali.

Makfoeld, D. 1992. Polifenol. Pusat Antar Study Universitas. Pangan dan Gizi Universitas Gadjah Mada, Yogyakarta.

Maulidzy, A. Z. dan A. Dwijayanti. 2016. Perbandingan aktivitas antioksidan dan kadar tanin ekstrak pegagan dengan produk jadi pegagan. eJurnal Kedokteran Indonesia. 4(1):15-20.

Meena H., H. K. Pandey, P. Pandey, M. C. Arya, dan Ahmed Z. 2002. Evaluation of antioxidant activity of two important memory enhancing medicinal plants Baccopa monnieri and Centella asiatica. Indian J. Pharmacol. (7)44:114-121.

Meilgaard, M., G. V. Civille dan B. T. Carr. 2000. Sensory Evaluation Techniques. CRC Presss, Florida.

Padua, L.S., Bunyaprahatsara, dan R.H.M.J. Lemmens. 1999. Plant Resources of South-East Asia, medicinal and poisonous plants. Medicinal and Poisonous Plants 1. 12(1):1-11.

Pokorny, J., N. Yanishleva, dan M. Gordon. 2001. Antioxidant in Food. Woodhead Publishing Ltd., England.

Rahmawati, F., G. Dwiyanti dan H. Sholihin. 2013. Kajian Aktivitas Antioksidan Produk Olahan Buah Jambu Biji Merah (Psidium Guajava L.). Skripsi. Tidak dipublikasi. Program Studi Kimia, Jurusan Pendidikan Kimia Fakultas Pendidikan Matematika dan Ilmu pengetahuan Alam. Universitas Pendidikan Indonesia, Bandung.

Ramdhan, T. dan S. Aminah. 2014. Pengaruh pemasakan terhadap kandungan antioksidan sayuran. Buletin Pertanian Perkotaan. 4(2):7-13.

Sari, P.W.N., I.B.P. Gunadnya, dan G. Arda .2017. Penentuan umur simpan loloh piduh dengan metode accelerated shelf life testing (ASLT) menggunakan pendekatan model arrhenius. Jurnal Beta (Biosistem dan Teknik Pertanian). 5(1):28-34.

Sharma R. dan Jaimala. 2003. Alteration of acid phosphatase activity in the liver of gamma irradiated mouse by Centella asiatica. 17(1\&2):1-9.

Soekarto, S. T. 1985. Penilaian Organoleptik untuk Industri Pangan dan Hasil Pertanian. Bhratara Karya Aksara. Jakarta.

Subban R., A. Veerakumar, R. Manimaran, K. M. Hashim, dan I. Balachandran. 2008. Two new flavonoids from Centella asiatica (Linn.). J Nat Med. 62:369373.

Sudarmadji, S. B. Haryono dan Suhardi. 1997. Prosedur Analisa Untuk Bahan Makanan dan Pertanian. Liberty. Yogyakarta.

Suyitno. 1989. Rekayasa Pangan. PAU Pangan dan Gizi. UGM Press. Yogyakarta.

Steel, R.G.D. dan J.H. Torrie. 1993. Prinsip dan Prosedur Statistika. Terjemahan Bambang Sumantri. Gramedia, Jakarta

Tusta, K., 2016. Pembuatan Loloh Don Piduh (Centella asiatica L.). Wawancara. Denpasar. 
Winarno, F. G. 1982. Madu: Teknologi Khasiat dan Analisa. Ghalia Indonesia. Jakarta.

Winarno, F. G. 2002. Kimia Pangan dan Gizi. Gramedia Pustaka Utama, Jakarta.

Winarto, W. R. dan M. Surbakti. 2003.

Khasiat dan Manfaat Pegagan (Centella asiatica L). Agromedia Pustaka, Jakarta. 